Available online at www.jmle.org

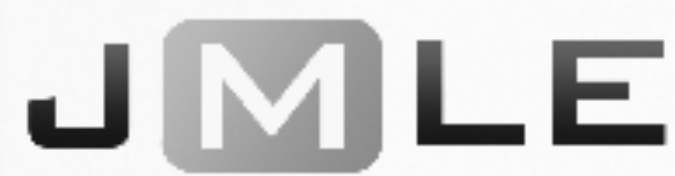

The National Association for Media Literacy Education's

Journal of Media Literacy Education 10 (1), 134 - 147

\title{
Too Much of a Good Thing? How Teachers' Enthusiasm May Lead to Protectionism in Exploring Media \& Gender
}

\author{
Elizaveta Friesem \\ Media Education Lab
}

\begin{abstract}
Challenges of media and gender literacy classes include the danger of steering students towards "right" interpretations of media texts while simplifying the complex relationship between audiences and media texts. The current paper describes a case study that focused on two high school teachers who were motivated by their protectionist concerns to analyze media representations of gender with students. The study aims to answer the question: Can teachers' enthusiasm lead to protectionism in media and gender classes, and if so, what does that look like? The author concludes that teachers passionate about shielding students from problematic ideologies may miss out on the complexity of media representations and students' opinions.
\end{abstract}

Keywords: gender, media representations, critical pedagogy, protectionism, high school

On a hot September day of 2014, I was sitting in a classroom of an East Coast high school, listening to a teacher (I will call him Michael) eloquently talking to students about the media. Passionate about critical pedagogy (Dewey, 2008[1916]; Freire, 1970) Michael was trying to persuade young people how crucial it is for them to use critical theory for analyzing media texts: "The media is [sic] trying to eat you, get money from you, while you are getting a screwed up perspective about what is normal in life!" According to the teacher, to protect themselves students needed to "read" media representations through seven critical lenses: feminist (patriarchal oppression), gender (femininity and masculinity as cultural constructs), archetypal (narrative designs and character types), Marxist (power and social classes), historical (inconsistencies with historic reality), psychological (characters' psychology), and reader-response (multiplicity of interpretations) (Appleman, 2000). Observing the classes taught by Michael and his colleague whom I shall call Rosey, who used the same pedagogical approach, I discovered that the first two lenses were of special importance for them. The teachers' passion stemmed from their conviction that gender inequalities exist, and that they are reinforced by the media. 
Many media scholars now believe that people are not brainwashed by the media (Carter et al., 2015). Some point out that the media do not create inequalities that exist in society but reflect them (Sternheimer, 2013). However, a number of people both inside and outside of academia still argue that the media make people act in certain, often problematic, ways. In terms of gender, scholars claim that media representations force audiences into limiting gender scripts, promote unrealistic beauty ideals, create eating disorders, and contribute to violence against women by turning them into sexualized objects (Durham, 2008; Jhally, 2006; Levin \& Kilbourne, 2006).

During my visits to classes taught by Michael and Rosey, I kept these debates in mind. My goal was to see how the teachers managed to find a balance in this complexity, and how their passion as activists fighting for gender equality impacted the way they were interacting with students. On the following pages I talk about roots of these teachers' enthusiasm, its manifestations in the classroom, and challenges that the use of critical pedagogy and media literacy education fueled by protectionist concerns may create for having nuanced conversations with students.

The small case study that I present in this paper is not representative of all enthusiastic educators who discuss media representations of gender in the classroom. In addition, I admit that my interpretations of classroom interactions that I observed are subjective. I have chosen to use the first-person voice in order to acknowledge this subjectivity and to remind my readers about it throughout the essay. Keeping these limitations in mind, I hope that my findings will encourage media literacy instructors to reflect on their practices by asking themselves whether their enthusiasm about issues of gender may sometimes be excessive and lead to undesirable results.

\section{Media and Gender Literacy: It's Complicated}

Our gender identities are shaped through interactions with a variety of social institutions, such as family (Fine, 2010), school (Pascoe, 2007), religion (Rubin, 1993[1984]) - and the media, which enter the life of children from an early age (Zero to Eight, 2016). However, this does not mean that people are duped or forced into reproducing gender scripts. Scholarship on audience reception suggests that audiences are agentic - they are actively using media texts for their own purposes and interpreting them in a variety of ways (Bobo, 2002; Cooper, 1999; Rand, 1995). Media fragmentation and the complexity of media texts also make it difficult to argue that media audiences are brainwashed into reproducing gender norms. Examining media representations of gender in the classroom allows educators to have important discussions with students about gender inequalities; nevertheless, these discussions do not need to be framed in terms of blaming the media.

At the same time, public discourse about the media is often colored by fear and blame (Freedman, 2002; Sternheimer, 2013), which might impact the way media and gender literacy classes are actually taught. Although many scholars believe that the relationship between people and the media is nuanced, authors and activists who focus on portraying the media in a strictly negative light 
somehow have more power to capture the public's imagination. Popular writer, speaker, and activist Jean Kilbourne has created numerous written works and videos analyzing images of women in advertising. She traces links between these images and multiple social issues, such as eating disorders, violence, and addiction (Kilbourne, 1999). Influential speaker and filmmaker Sut Jhally focuses on what he describes as dangerous ideals of femininity promoted by the entertainment industry (Jhally, 2006). These and many other authors use their conviction and passion to argue that educators need to protect students from problematic images of gender that inundate the modern culture.

It is not at all surprising that some teachers exposed to such passionate calls for action may choose to develop their students' media and gender literacy. It is also not surprising that some of these teachers may decide to focus on harmful ideologies embedded in media texts. However, in light of the more nuanced scholarship on media and gender, it is important to ask ourselves where the efforts to enlighten students about dangers lurking in media representations of gender may lead us.

Courses that encourage students to reflect on media representations of gender exist in a number of colleges and universities, and in some K-12 schools. However, very little is still known about what happens in these classrooms, what works and what does not work, and how such courses can be made more effective (Friesem, 2016; Keown, 2013; Ryden, 2001). While the case study presented on the following pages is not representative of all media and gender literacy classes, it is meant to contribute to the discussion about the importance of having a nuanced conversation about gender representations with students.

\section{Challenges of Teaching about Media and Gender}

A number of authors discuss challenges that educators who teach students about the media should take into consideration (Buckingham, 2003; Friesem, 2017; Hobbs, 2011; Turnbull, 1998). These challenges include students' resistance, inability of teachers to connect to young people's experiences, the danger of reinforcing stereotypes, and the tendency to steer young people towards "right" interpretations.

Buckingham (2003) points out that when teachers try to make students aware of problematic media representations they run the risk of oversimplifying media texts they analyze. If educators offer students only a simplified explanation of how media representations function, young people might be unable to go from it to a more nuanced understanding. Discussing a series of lessons about images of women in the media, Buckingham writes:

Although the material that was being studied was fairly complex, the argument was constantly reduced to simplistic conclusions about the negative influence of the media: women's magazines, which were the primary focus of study, were implicitly accused of a straightforward form of victimization of women readers. The pre-defined critical position effectively prevented the students from arriving at a more nuanced account 
which did justice to their everyday reading and uses of these texts. (Emphasis in original) (pp. 117-118)

Buckingham (2003) and Hobbs (2011) discuss the danger of losing nuances when talking about the role of the media in students' lives. Guided by the best intentions, teachers passionate about their subject may overemphasize the idea that the media have negative effects on people, without taking into consideration audiences' agency. This might happen when critical pedagogues or media literacy educators lean towards protectionism - a tendency to assume that students need to be shielded against the media's negative influence (Buckingham, 1998).

To contextualize the danger of steering students towards "right" answers when analyzing media texts it is necessary to talk about two major paradigms within media literacy education and critical pedagogy: protectionism and empowerment (Buckingham, 1998; Hobbs \& Tuzel, 2015). Although these paradigms are often described as polar opposites, educational practices can be usually placed somewhere in-between on the protectionism-empowerment continuum.

Protectionism in education bears the influence of scholarship on media effects; both are based on the idea that media texts can have direct influence on audiences, and that this impact is often problematic. Empowerment as an instructional approach, same as theories of active audiences in media studies, offers a much more optimistic point of view, describing audiences as potentially agentic, learning from the media and using media tools effectively. If protectionism attempts to save people from negative media effects by giving them media analysis skills, empowerment model aims to help students use media texts and tools to their full potential.

Early approaches to critical pedagogy and media literacy education often positioned young people as victims of ideologies (Buckingham, 1998), mirroring concerns that fuelled research on media effects. Most media scholars have by now recognized that the relationship between audiences and media texts is complex, and audiences are neither "zombified" by the media, nor completely free from the media's influence (Carter et al., 2015). Similarly, some media literacy and critical pedagogy educators now believe that "children are a much more sophisticated and critical audience than they are conventionally assumed to be" (Buckingham, 1998, p. 10). These educators do not automatically assume students' knowledge to be invalid; they use it to better understand students and engage them though the pedagogy of inquiry (Hobbs, 1998).

However, it is also not uncommon for educators to choose a more protectionist stance, which can be explained by the popularity of the media effects paradigm discussed in the previous section. This is when the danger of steering students towards "right" answers and ignoring the complexity of media texts may become a problem. Although a number of scholars discuss protectionism and empowerment in educational practices (Hobbs \& Tuzel, 2015), the literature says little about challenges of balancing between these tendencies in the classroom where students dissect media representations of gender (Buckingham, 2003; Turnbull, 1998). 
Collecting data for this study, I was guided by the following question: Can teachers' enthusiasm in media and gender classes lead to protectionism, and if so, what does that look like? Enthusiasm in the classroom appears to be a key to successful teaching and learning. But can there be too much of a good thing?

\section{Methods}

I used the case study approach and collected data over a period of two months in the fall of 2014 focusing on three units (parts of three separate classes) taught by two teachers in a suburban school located on the East Coast of the United States. Each of the three units involved analysis of media texts and discussions about media representations of gender. My data included notes from participant observation in the classroom and interviews with the teachers.

Following the rules set forth by the Institutional Review Board (IRB), which had previously approved the study, the teachers were orally informed about the nature of the study and asked to sign consent forms giving me permission to interview, digitally record, and quote them. In order to maintain participants' confidentiality, I use pseudonyms Michael and Rosey, and call the school where I conducted my study West Cityville High School.

West Cityville High School is a suburban public school that teaches students from grades 9 to 12 . It has about 1,000 students and 90 teachers. Although West Cityville may be seen as a part of Cityville (an East Coast city), it is considered to be a separate town. As of the census of 2010, the population of West Cityville was approximately 32,000 people. The population is mostly White (close to 90\%), with African-Americans and Hispanic/Latinos being the largest minorities (about 4\% each). Median household income in West Cityville is about $\$ 50,000$, with a little over $10 \%$ of families below poverty level.

Throughout September and October of 2014, I visited West Cityville High School 17 times, and each time stayed for 4 to 7 hours. In order to observe as much as I could and to see the progress of the classes, I visited the school three times a week. I interviewed Michael and Rosey separately using a semi-structured interview guide. The interview with Michael lasted 2.5 hours and the interview with Rosey - 40 minutes, due to differences in the teachers' availability, personalities and style of talking. I asked them to describe their teaching philosophy, instructional approaches, and motivations for teaching about media and gender. To analyze the data, I used elements of the grounded theory (Glaser \& Strauss, 1967).

\section{Enthusiasm about the Subject}

My interview with Michael revealed his belief that critical theory is inherently empowering for students, who can use this new tool to see ideologies imposed on them by society. For this highly enthusiastic and motivated teacher, the critical lenses were valuable because "looking at the world through multiple perspectives we can have a healthier understanding of the information that's being presented to us."

Rosey and Michael cared about their students' media and gender literacy because they had a special emotional connection to this topic. Both teachers 
talked with conviction about fighting against rigid gender roles. During our long conversations and my observations in the classroom I started to see why this fight was so important to them.

Michael told me that growing up he experienced pressure to conform to standards of masculinity: "I have a memory from third grade of a kid making fun of me because I wore a pink shirt to school... I was always very sensitive and emotional, and was made to feel ashamed of that." He described this pressure as a "force that was making [him] feel alienated."

Michael grew up in a religious Catholic family, and used to be an altar boy. Growing up he made friends with people whom his religion did not accept. That further complicated things, and made him seriously question the culture he was a part of.

Then I became friends with people who were gay. And I had an aunt who was a lesbian. And I knew that those people were no different than anyone else, but my religion was telling me that they were a sin against nature. And the heterosexual patriarchal society that surrounded me also told me that they were wrong. And my aunt Betsy was one of the nicest people I knew. And... I'm, like, getting upset thinking about it... 'Cause, like, it's so fucked up that you can be a kid and people could tell you that the people you love are wrong, based on their ideological belief.

Michael's story implied that he saw critical theory — and gender theory in particular - as liberatory both for him and for the students he was teaching: "Alienation is something that I understand. If I can get kids to have a cleaner view of the world that empowers them to not to kill themselves, or to not feel alone, then I'm doing something good."

Rosey appeared to be fueled primarily by her motivation to protect female students from harmful messages that they encounter: "The girls in my class are very beautiful human beings, they are very smart, but their whole life has taught them to just be quiet." Rosey told me that boys are also negatively affected by the media, but in a way that often hurts girls: "I just think that girls learn [from the media] how to be girls and boys learn how to treat girls, or what the ideal girl is for them."

Like Michael, Rosey's background predisposed her to be very sensitive to gender stereotypes. During one of the classes she told a story of how she had been bullied about her nose as a girl. Rosey hated her nose so much, that one day she gathered all the money she had and made an appointment with a plastic surgeon. However, when she was in the doctor's office for the first consultation, sitting in his big chair and listening to all the terrible things he had to tell about her nose, the absurdity of the situation struck her. She burst into laughter right in the chair, and left the office to never come back. Talking about the way gender stereotypes affect her, Rosey also mentioned that her family put much more pressure on her than on her brother to get married, which see saw as unfair.

For Michael and Rosey, helping students to "read" media texts through the critical lenses was not simply a job but a way to make a positive change in the 
world, a goal that went beyond working with students in the classroom. As Michael put it: "I just found in that a calling, an opportunity to do something in the world. Like, what's gonna be my thing, how I am gonna make my mark." The teachers took an active role in the school's Gay and Straight Alliance, and were willing to have conversations with students outside of class to help them better understand issues of gender. For instance, during the time when I was collecting the data, Michael found out about a female transgender student whom her peers were calling "it." Michael was actively looking for opportunities to talk one-onone to students who engaged in this bullying because he felt that the administration was not doing enough to stop it.

My evidence showed that the teachers I was observing were passionate about issues of media and gender due to their personalities, experiences and convictions. While this enthusiasm made their classes engaging and thoughtprovoking, it also led to a certain degree of protectionism, which I describe below.

\section{Protecting Students}

Both Rosey and Michael in one way or another discussed the need to protect young people from problematic media messages, especially media representations of gender. For example, Rosey said that her aim was to make sure that students "don't just treat other people and treat themselves based on a bunch of, like, propaganda that's pushed down their throats." At the same time, it appeared that empowering students was also an essential goal for the teachers. Michael told me that critical pedagogy taught him about the importance of "trying to get [students] to understand that I don't want them to be regurgitators of information, [but]... creators of information." Talking about his education philosophy, he explained: "I think that as much as I have to teach my students I have an equal amount to learn from them."

However, while during our conversations Michael talked about the balance of protecting students and empowering them, in the classroom I saw him leaning more towards the protectionist approach. On several occasions the teacher told students that they are negatively affected by ideologies embedded in media messages. For example, he said: "You can say, it does not affect me, but you were exposed to that since you were born, and by the time you were four these stereotypes have shaped your thinking." During one of the discussions with students about the media I heard him passionately say: "Recognize how these expectations were sold to you!"

Rosey made fewer strong statements in the classroom about negative media effects. On one occasion, however, she told a student whom I shall call Melissa: "You don't notice that because you have been brainwashed." On another occasion I witnessed the following discussion:

Rosey: Remember there was a song saying, like, fifty times, "I'm the man, I'm the man, I'm the man'?

Several students: Yeah! We love this song! 
Rosey: How can you like this song?! Will anybody make a song that says "I am the woman, I am the woman, I am the woman"?

In this case Rosey pronounced her judgment on a song whose message she deemed problematic, critiquing her students' enjoyment of this popular text.

At the same time, Rosey allowed students to express a variety of interpretations. For example, when Kevin, who was often critical of the teachers' messages, told her: "I think we should put money into hunger, and then into feminism, it is more important," she did not silence him. Instead, she replied: "We can do both things at once," and even stopped a female student who started to argue angrily with the boy. When Melissa, another resistant student, said that she did not see messages sent by women's fashion magazines as problematic, Rosey replied: "I like your observations, you are very honest."

Michael and Rosey seemed to value the empowerment educational model; however, as they were interacting with students, the protectionism model often took over their instructional strategies. In the next section I describe in more detail how the teachers, motivated to shield students from negative media effects, sometimes missed nuances of the relationship between audiences and complex media texts.

\section{Complexity of Media Representations}

I previously mentioned that the teachers chose to include the readerresponse lens in the list of critical theories to discuss. However, this lens did not receive much attention neither from them, nor from students. The definition of this lens provided by Appleman (2000), the book that Rosey and Michael used in their class, is in line with what the scholarship on active audiences says: "[L]iterature has no objective meaning or existence. People bring their own thoughts, moods, and experiences to whatever text they are reading and get out of it whatever they happen to, based on their own expectations and ideas" (p. 157). A potential explanation for the lack of emphasis on this particular lens might come from the teachers' fear of allowing students to produce their own interpretations.

As much as Michael and Rosey wanted students to express their voices, they were also afraid to let these voices reflect harmful ideologies, which, according to the teachers, affected students since the day they were born. Furthermore, during my observations I did not see much discussion about the sophistication of media representations, about the variety of possible interpretations of media texts, or about active audiences.

The units that I observed featured three major activities: screening the films Toy Story and Pocahontas, and a Hacked Ads assignment. Michael and Rosey used Toy Story to model analyzing a media text through the critical lenses. Watching Pocahontas was intended to let students practice using the critical lenses independently. The Hacked Ads assignment involved analyzing a magazine cover or ad, and creating a collage that would expose and/or undermine the text's hidden messages. 
As the class was analyzing media texts during these activities, Michael and Rosey noted on a couple of occasions that what they were offering were their interpretations. At the same time, the teachers never discussed alternative interpretations, and did not provide many opportunities for students to challenge their opinions.

While the class was watching Toy Story, Michael and Rosey were giving explanations for almost every scene. Using the feminist lens they pointed out how leadership roles were taken by male characters (Buzz and Woody), while women were portrayed as damsels in distress (Bo Peep). Using the gender lens the teachers argued that male characters were shown to solve their problems through violence. From time to time Michael and Rosey asked students questions, e.g., "How do these men solve their problem?" As Michael and Rosey had particular ideas in mind, they were guiding young people to form similar interpretations. Thus the questions were used not to elicit students' opinions but to make sure that they understood how to use critical lenses correctly.

Before the screening of Pocahontas, Michael told students: "Remember that annoying thing I did as we were watching Toy Story? I was talking all the time... Now I am not going to do that." Nevertheless, it was difficult for Michael to relinquish control and let students create their own interpretations. As soon as the movie started in one of the classes, Michael jumped up from his seat and said almost with indignation: "It starts in London?!" Michael was pointing out to students that a film about a Native American girl did not start by portraying her world but rather the world of the future settlers.

As the movie was playing, Michael occasionally made remarks and asked questions that revealed his interpretations. When the screen showed Englishmen in the sea travelling to the New World, he said: "So I just ask you, where are the women?" Stopping the movie at another place, the teacher told students: "I am going to throw you a bone. How does Pocahontas' reaction to John Smith [when she sees him for the first time] reinforce what is valuable about male gender?.. It is showing us what the ideal male is!" In this case he asked students a question and then immediately answered it himself. Michael was so enthusiastic about critical theory that he could not help analyzing things himself.

When time came to do the Hacked Ads assignment, Michael had a heated debate about Cosmopolitan covers with one of the classes. This debate deserves special attention because it illustrates how too much enthusiasm about protecting students from harmful media messages may lead to silencing students' interpretations and discouraging a dialogue. The discussion started when Michael showed young people a cover with the actress Hayden Panettiere on it (see Figure 1 which shows an image of the magazine cover used in the lesson) and asked what they were seeing. Hayden is portrayed wearing a short white strapless dress that accentuates her body and reveals the cleavage.

A couple of students said that the actress was sexualized. However, some others did not agree. For example, one male student noted that she looked "like any woman on her wedding day." To persuade students that Hayden Panettiere was indeed sexualized, Michael focused on her cleavage. Then a student I shall call Rodrigo said: "When guys look at girls, they look at their face, it is 
scientifically proven," to what Michael replied: "Don't be so confident about something you don't know!" Then the teacher pointed out the actress's pose: "Look at how she stands, is it natural?" (Hayden has one hand on her hip and the other one resting on her thigh). To which several students answered "Yes!" Michael started mocking the pose to show that it does not look natural at all, and many students laughed. Eventually, one student said: "It is unnatural and nobody looks like that."

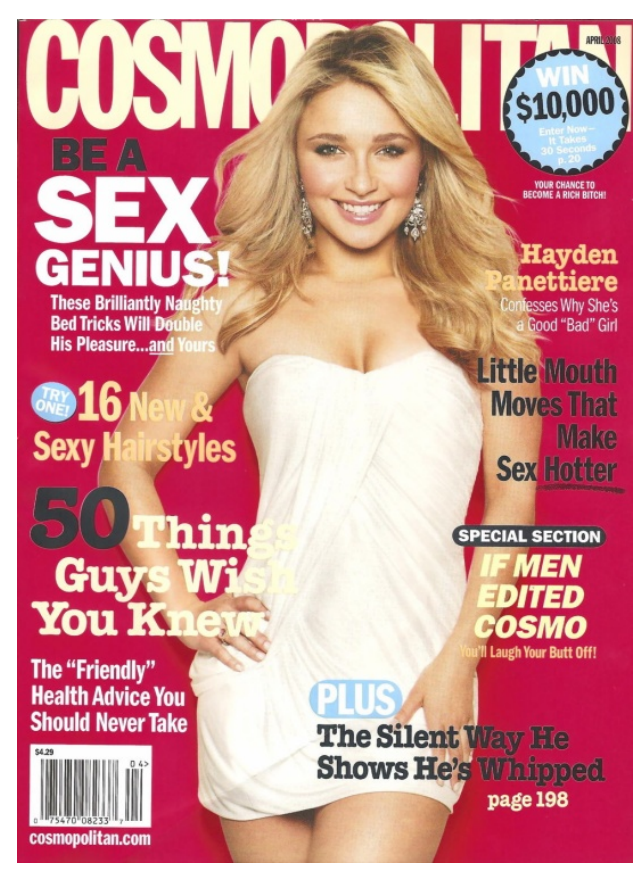

Figure 1

Cosmopolitan cover that Michael used in his class

During this discussion Michael was getting irritated. He made some harsh remarks to students who disagreed with his interpretations. When the teacher argued that the image on the cover is constructed to draw the viewer's attention to Hayden Panettiere's cleavage, one student said: "You can see her boobs because you imagine that!" To that Michael retorted: "You imagine shit!" When Michael said "You cannot see men on magazine covers standing in these poses... they are unnatural," one student disagreed with him, so the teacher told him: "Chill, you are undermining the conversation." While Michael's enthusiasm about helping students see problematic media representations was laudable, too much of this enthusiasm led to excessive protectionism as the teacher was actively trying to prove to students how they had been blinded by harmful ideologies.

Michael's remarks showed that for him this discussion was not about having students voice their interpretations, but about persuading them to accept his opinion. Towards the end of the debate Michael said: "Cosmo is a microcosm, I don't see how you can argue about that with me! It shows... that women are sex objects... This evidence is overwhelming, why are you resistant considering this 
mounting evidence?" Continuing his monologue, the teacher argued: "You have been duped to think that is natural when you were kids, before you created defenses... It damages not only females in this room but men too. You have men and women with low self-esteem because of this shit." Michael's emotional statements during the Cosmopolitan debate revealed his protectionist stance and his activism targeted against harmful media texts.

The question remains whether students benefited from the conversation where the teacher's opinion was presented as the only accurate interpretation. Is such emphasis on one opinion helpful for the development of critical thinking, which is considered the key element of media literacy (Hobbs, 2011)? The contradiction I could see in Michael and Rosey's actions was that, although the teachers noted that there can be different interpretations of media texts, they appeared to be concerned that young people might express "wrong" ideas. As a result, nuances of media representations and audiences' interpretations were lost, while alternative opinions were not explored.

\section{Honoring Student's Interpretations}

The current case study suggests that media and gender literacy classes may suffer from a lack of emphasis on students' interpretations and their background knowledge. This was demonstrated in the teaching style, which exemplified protectionist approach in spite of Michael and Rosey's intention to empower their students through critical pedagogy.

Although most media literacy educators balance between protectionism and empowerment, many may be tempted to shield students from problematic media messages. The fear of harmful ideologies embedded in media texts fuels teachers to discuss gender stereotypes in the first place. The leaning towards the protectionist approach may be combined with the lack of knowledge about the complexity of the relationship between media texts and audiences, and about the sophistication of media representations. Unless educators who teach about media and gender took a course in media studies, they are most probably not aware of the knowledge accumulated within this discipline. Thus, it is not at all surprising that discussions in media and gender classes may lack some nuance.

Teachers may be tempted to focus on their own interpretations of media texts and dismiss students' ideas, especially if these appear to reflect harmful ideologies. By focusing on their own interpretations educators may miss an opportunity to have more meaningful discussions with students and to use young people's opinions as teachable moments in the classroom.

Honoring students' points of view can add an important dimension to the process of developing young people's media and gender literacy. Although students still have a lot to learn about the media, teachers should remember that young people come to classes with important knowledge about media texts and tools. The empowerment model of media literacy education suggests that instructors should treat young people as experts in their own right (Hobbs, 2011). Teachers can learn a lot from students-about the latest music trends, social network tools, and youth culture in general. They can then use this knowledge to better connect to students and their world. 
Applying the inquiry-based approach advocated by media literacy educators (Hobbs, 1998), teachers can start media and gender classes by asking students about their ideas and experiences, and then built classroom activities around gaps in students' knowledge that they will discover, while at the same time showing interest in students' knowledge and not dismissing it as irrelevant. Teachers should also learn to negotiate their own discomfort and defensiveness when faced with what they perceive as resistance. Letting students express their opinions can lead to heated debates that teachers might want to avoid. Instead of arguing with students, teachers can serve as facilitators in debates between them, helping young people to exchange their opinions in a respectful and polite manner.

Letting students express their ideas is challenging as young people can voice opinions that go against things teachers believe in. But many students may already know something about gender stereotypes and inequalities - in this sense, they possess important pieces of a puzzle. In order to help students put these pieces together, teachers should first find out what they are. When they hear opinions that expose students' biases, a conversation about implicit attitudes behind these biases can begin (Rudman, 2004).

If teachers do not find out their students' opinions, they may end up alienating students who disagree, and preaching to the choir in case of students who already share teachers' beliefs. By trying to persuade students that media texts are harmful and that equality is important teachers will reinforce young people's assumptions without complicating them.

\section{Conclusion}

If you are an educator passionate about gender equality, you may decide to discuss media representations of gender with your students. The case study that I describe in this paper is not representative of all media and gender literacy classes, so your approach may be very different from Michael's and Rosey's instructional strategies. The goal of my research was not to make generalizations but to help educators reflect on their practices. Is it possible that your enthusiasm and passion (which are undeniably important for an educator) make you overemphasize your interpretation of media texts, practices, and spaces while missing opportunities to have a dialogue with your students?

The case of Michael and Rosey reveals that, in terms of protectionism and empowerment, there may be a contradiction between teachers' philosophy and their actions in the classroom. It is, therefore, essential to be aware of our own biases as educators and to make sure that they do not overly affect our classroom practices. It is important to remember that, while mediated communication reveals important truths about the social dynamics, the media are likely not the only or the primary force shaping people's identities and guiding their actions. However, media literacy education can be used to start important conversations about controversial social issues such as gender.

While there is nothing bad in wanting to protect our students from harmful ideologies, if we ignore nuanced research about people's relationship with the media we run the risk of oversimplifying the problem, alienating students who do 
not accept the "right" answers, and missing out on the complexity of students" opinions. We may, thus, ignore valuable teaching moments that can help our students develop their critical thinking skills, which are essential for being truly media literate.

\section{References}

Appleman, Deborah. Critical Encounters in High School English. New York: Teachers College Press, 2000.

Bobo, Jacqueline. "The Color Purple: Black Women as Cultural Readers," in Say It Loud! African-American Audiences, Media, and Identity, edited by Robin R. Means Coleman, 205-228. New York: Routledge, 2002.

Buckingham, David. "Introduction: Fantasies of Empowerment? Radical Pedagogy and Popular Culture," in Teaching Popular Culture: Beyond Radical Pedagogy, edited by David Buckingham, 1-17. Bristol: UCL Press, 1998.

Buckingham, David. Media Education: Literacy, Learning and Contemporary Culture. Malden: Polity, 2003.

Carter, C., Steiner, L. and McLaughlin, L. (Eds). The Routledge Companion to Media \& Gender. New York: Routledge, 2015.

Cooper, B. "The Relevancy and Gender Identity in Spectators' Interpretations of Thelma \& Louise." Critical Studies in Mass Communication 16, no.1 (1999): 20-41.

Dewey, J. Democracy and Education. Radford, Wilder Publications, 2008 [1916].

Durham, M.G. The Lolita Effect: The Media Sexualization of Young Girls and What We Can Do about It. Woodstock: Overlook Press, 2008.

Fine, C. Delusions of Gender: How our Minds, Society, and Neurosexism Create Difference. New York: W.W. Norton \& Company, 2010.

Freire, P. Pedagogy of the Oppressed, translated by Myra Bergman Ramos. New York: Herder and Herder, 1970.

Freedman, J.L. Media Violence and Its Effect on Aggression: Assessing the Scientific Evidence. Toronto: University of Toronto Press, 2002.

Friesem, E. "Drawing on Media Studies, Gender Studies and Media Literacy Education to Develop an Interdisciplinary Approach to Media and Gender Classes." Journal of Communication Inquiry 40, no. 4 (2016), 370-390.

Friesem, E. "Half-Changed Minds: How Hegemony Shapes Youth' Perception of Media and Gender." Media Education Research Journal 7, no.2 (2017): 6583.

Glaser, B. and Strauss, A., The Discovery of Grounded Theory: Strategies for Qualitative Research. Chicago: Aldine, 1967.

Hobbs, R. "The Seven Great Debates in the Media Literacy Movement." Journal of Communication 48, no.1 (1998): 16-32.

Hobbs, R. Digital and Media Literacy: Connecting Course and Classroom. Thousand Oakes: Corwin Press, 2011. 
Hobbs, R. and Tuzel, S. "Teacher Motivations for Digital and Media Literacy: An Examination of Turkish Educators." British Journal of Educational Technology (online version) (2015): 1-16.

Jhally, S. The Spectacle of Accumulation: Essays in Culture, Media, and Politics. New York: Peter Lang, 2006.

Keown, E.L. "The Impact of an Art-Based Media Literacy Curriculum on the Leadership Self-Efficacy of Adolescent Girls," unpublished doctoral dissertation. Edgewood College, Madison, WI, 2013.

Kilbourne, J. Deadly Persuasion: Why Women and Girls Must Fight the Addictive Power of Advertising. New York: The Free Press, 1999.

Levin, D. and Kilbourne, J. So Sexy So Soon: The New Sexualized Childhood and What Parents Can Do to Protect Their Kids. New York: Ballantine Books, 2006.

Pascoe, C.J. Dude, You Are a Fag: Masculinity and Sexuality in High School. Berkley: University of California Press, 2007.

Rand, E. Barbie's Queer Accessories. Durham: Duke University Press, 1995.

Ravitch, D. Reign of Error: The Hoax of the Privatization Movement and the Danger to America's Public Schools. New York: Vintage Books, 2013.

Rubin, G. "Thinking Sex: Notes for a Radical Theory of the Politics of Sexuality," in The Lesbian and Gay Studies Reader, edited by Henry Abelove, Michele Aina Barale and David M. Halperin, 3-44. New York: Routledge, 1993 [1984].

Rudman, L.A. "Sources of Implicit Attitudes." Current Directions in Psychological Science 13, no.2 (2004): 79-82.

Ryden, P.A. "Fighting Fire with Fire: An Analysis of Critical Media Literacy Videos," unpublished doctoral dissertation. Purdue University, West Lafayette, IN, 2001.

Sternheimer, K. Connecting Social Problems and Popular Culture: Why Media is Not the Answer. Philadelphia: Westview Press, 2013.

Turnbull, S. "Dealing with Feeling: Why Girl Number 20 Still Doesn't Answer. In Teaching Popular Culture: Beyond Radical Pedagogy, edited by David Buckingham, 88-106. London: UCL Press, 1998.

“Zero to Eight: Children's Media Use in America," accessed July 09, 2016, https://www.commonsensemedia.org/research/zero-to-eight-childrensmedia-usein-america 